\title{
Notas sobre la democracia y la revolución en Nicaragua*
}

\author{
Marvin Ortega \\ Director del Instituto de Investigaciones ITZTANI \\ Managua, Nicaragua 1989
}

\section{Algunas vislones de la democracla sandinista}

En Nicaragua existen muy pocos estudios académicos públicados, que aborden la naturaleza del modelo democrático de la revolución sandinista'. No pasa lo mismo con ensayos sobre la democracia, en los que se analizan aspectos particulares o comportamientos específicos de distintos sectores sociales. Su producción es bastante extensa, aún cuando la mayoría de ellos permanecen inéditos. ${ }^{2}$. En forma de folleto o como colección de discursos, se han publicado decenas de intervenciones de los dirigentes de la revolución, en la cual se aborda la experiencia democrática de la revolución ${ }^{3}$.

Por lo menos una docena de revistas de circulación nacional publican con regularidad artículos, ensayos y comentarios periódisticos en los que se exponen las distintas visiones que sobre la democracia circulan en el país ${ }^{4}$. Finalmente en el exterior, con una reducida circulación en Nicaragua, y sobre todo como colección de ensayos, se han publicado numerosos libros que intenta, desde diferentes ópticas, discutir la democracia en la revolución.

En la oposición al gobierno del FSLN se encuentran dos tipos de puntos de vista, que encaran el modelo democrático de la revolución

- Presentada en el seminario "Cultura Polltica y Democracia en América Central", realizado por el Programa de Post-Grado de sociologla de la Universidad de Costa Rica del 26 al 29 de julio de 1989. 
sandinista desde perspectivas diferentes. Uno de ellos es identificable entre los partidos de derecha, que califican el modelo como manxista, totalitario y antidemocrático; a la izquierda, los partidos de centro, los marxistas-leninistas y trotskistas, consideran el modelo sandinista como un régimen autoritario, anti-popular, encabezado por un gobierno pequeño-burgés, de orientación liberal nacionalista.

Ninguna de las corrientes (derecha, centro e izquierda), que operan desde el interior de el pais ${ }^{5}$, ha publicado estudios o ensayos sobre sus posiciones, encontrandose sus críticas en articulos periodisticos. La extrema derecha, por su lado, ha publicado en paises centroamericanos algunos estudios en los que explican lo que serla para ellos la naturaleza totalitaria del sandinismo ${ }^{\circ}$.

En otra dimensión, las versiones más identificadas o militantes con la revolución, intentan presentar la democracia sandinista como un modelo original, llamado comunmente democracia participativa. Quienes definen la revolución dentro de esa estrategia, se sub-dividen asimismo en varias corrientes.

a) Existen los que caracterizan el modelo sandinista a partir de las condiciones especificas en las que se desarrolla la revolución, tomando en cuenta la pobreza del pals, la agresión norteamericana, y las condiciones geopolíticas de una pequena nación situada en una parte del continente que ha sido considerada por los Estados Unidos como su traspatio. Consideran que estos hechos han impuesto una alianza de clases que define en última instancia a la revolución, destacándose la existencia de un modelo pluralista, de economía mixta y no-alineado, cuya base es la Unidad Nacional de todos los nicaragūenses en defensa de la soberania nacional frente a la agresión imperialista, unidad esta, sin embargo, cuya hegemonia supuestamente descansa en el poder de los sectores populares;

b) Con una opción muy parecida hay quienes comparten aspectos del criterio anterior, pero sin valorar como determinantes las condiciones sociales y geopoliticas del pais; para quienes hacen estas consideraciones el pluralismo y la economia mixta son apenas una concepción táctica, insistiendo más en el supuesto carácter socialista y obrerocampesino de la revolución sandinista;

c) Una tercera postura considera que la democracia participativa de la revolución es posible por ser esta un modelo nacionalista, de carácter plural, fundado en el apoyo de todas las clases sociales del pais.

Las dos primeras corrientes han identiticado a la revolución sandinista como parte de la revolución socialista mundial, y las diferencias 
de matices se refieren sobre todo al carácter más o menos socializante que le atribuyen a esta etapa.

La última corriente, ha insistido sobre todo en la naturaleza sandinista de la revolución, con muy poca preocupación de si pertenece o no a la revolución socialista mundial, y más inclinada a aceptar que se trata de una experiencia nueva que no se puede insertar en ninguna de las vertientes de lo que serla el socialismo real o ideal discutidas hasta hoy.

Hasta aquí hemos intentado delinear cuales son las visiones más importantes sobre la democracia que tienen presencia en Nicaragua, y que apuestan a una $u$ otra alternativa democrática. No pretendemos extendernos en detalles al respecto, ya que intentaremos a lo largo del trabajo, comentar estas distintas visiones, mientras avanzamos en la caracterización del modelo de democracia de la revolución sandinista.

\section{La revolución en el poder}

El discurso revolucionario que caracterizó la lucha contra la dictadura somocista, "tuvo en el sandinismo diferentes tonalidades antes de julio de 1979. Una de ellas, con marcado énfasis proletario, reivindico una revolución de corte socialista; otra tendencia, con un perfil campesinista, también se planteo la lucha por el socialismo; una tercera vía abogó abiertamente, con un lenguaje moderado, por una revolución nacionalista capaz de gobernar con una alianza de clases amplia?.

Pero más allá de las diferencias las tendencias tenían un mensaje común. Los sandinistas se presentaron siempre como un movimiento anti-somocista, nacionalista y anti-imperialista, que pretendla derrocar a la dictadura y construir una sociedad revolucionaria y anti-capitalista, dispuesta a enfrentar las desigualdades sociales; una revolución de los más pobres en contra del somocismo como representante de los más ricos. Una revolución que tendria que destruir el poder político y económico de los grandes capitalistas, para transferirlo a las clases populares, democratizando el país sobre todo por la via de la redistribución de los recursos.

Electivamente, cuando se concretó el triunfo revolucionario, los esfuerzos del nuevo gobierno se dirigieron a destruir todo vestigio del viejo régimen, creando un gobiemo defensor de la soberania y la dignidad nacional; un gobierno que intentó disminuir las desigualdades sociales, abriendole las puertas de la participación política y económica a las clases más desposeidas.

Además, el triunfo unificó las corrientes sandinistas, desapareciendo 
las distintas opciones con que las tendencias compitieron antes de 1979, insistiendose mucho en la naturaleza plural, en la economla mixta y el no-alineamiento de la revolución. El FSLN, que en sus tres tendencias se habia mantenido como un partido de cuadros, poco antes del triunto y sobre todo después de la caida de la dictadura, se abrió a la militancia de millares de personas entusiasmadas por la estela victoriosa del partido sandinista unificado, nutriéndose como partido de revolucionarios sin experiencia política partidaria, de cuadros manxistas de todas las tendencias y de ex-militantes de partidos de la derecha o el centro.

Estos cambios provocaron modificaciones sensibles en la ideologla sandinista, introduciendo al seno partidario concepciones en las que primaba el sentido práctico, más que la ideología. De ahí que el sandinismo unificado se presenta en julio de 1979 con un tono mucho más suave que el lenguaje radical socializante con el que habla venido haciendo política desde su fundación. En ese sentido, la dirección que se le imprimió a la revolcuión fue en su práctica concreta, mucho más moderada de lo que el discurso precedente lo habia sido.

De hecho, cuando se dieron los primeros pasos para llevar adelante el proceso de transformaciones planteado por el programa sandinista, la legislación pretendió afectar solamente las empresas agropecuarias, industriales y comerciales propiedad de Somoza, su familia y sus principales aliados ${ }^{\circledR}$. Con esas medidas el nuevo gobierno pretendia respetar la alianza de clases que se creó durante la insurrección antisomocista, que incluia en ella a los capitalistas, aún cuando una postura de tal naturaleza fuera diferente al mensaje que durante casi veinte ahos defendió el sandinismo.

Pero la intencionalidad de esta política chocó con las tradiciones que la lucha anti-somocista había impreso en la militancia sandinista, y en las expectativas que la victoria hizo nacer en el pueblo. En 1979, entre los sectores populares estaba desarrollada con mucha intensidad la demanda anticapitalista, de manera que las presiones por la redistribución no se limitaron a las propiedades del dictador, y se transfirieron rápidamente hacia la propiedad capitalista en general.

La revolución -que incluía en el gobierno a representantes del capitał-, comenzó a ceder (no lo pudo evitar) frente a las presiones populares, y se nacionalizó gran parte de la propiedad capitalista, especialmente la más grande, independiente de sus vínculos pasados con el somocismo. Para el sandinismo esta demanda socializante de los sectores populares le era natural, de manera que no le resultó contradictorio, como partido político, abandonar la política de Unidad 
Nacional y el tono moderado de sus primeros dias, para adoptar una línea de ruptura con el capital. La justificación para aceptar un modelo más radical se buscó tanto en las presiones populares que en última instancia explicaban la existencia misma de la revolución, como en principios generales de justicia, apelándose a la autoridad de la revolución y a la conciencia de los grandes propietarios para que aceptaran una redistribución mayor de la riqueza.

El fenómeno fue precedido por la apertura politica que produjo la revolución. Derrotada la dictadura, la movilización del pueblo alcanzó a todos los sectores populares, promoviendo un desarrollo de la sociedad civil sin precedentes nacionales. La movilización y la organización, en los primeros momentos de la revolución, sirvió de estímulo para que el pueblo tomara en sus manos el ordenamiento de la vida cotidiana, mientras el nuevo gobierno, que apenas surgla, creaba la capacidad de gobernar.

La participación popular se generalizó, como la altemativa de base para la construcción del nuevo modelo democrático propugnado por la revolución. Los primeros pasos en ese sentido se dieron inmediatamente después de la insurrección, al destruirse las estructuras militares, politicas y sociales que representaron al viejo régimen, confiscando la propiedad somocista, y expropiando la mayor parte de las empresas grandes de los capitalistas ${ }^{\ominus}$. A la par surglan o se fortaleclan los sindicatos, los organismos barriales, las organizaciones juveniles, femeninas y gremiales, reivindicando un modelo democrático en el que los trabajadores tuvieran el derecho con su participación directa a decidir sobre su propia vida.

El proceso que chocó desde su comienzo con los defensores de la propiedad privada, al mismo tiempo que se convertía en una práctica cotidiana que involucró a la mayoría de la población, dando forma a un modelo de participación democrática en la política y la economla, que se enfrentaba como concepción teórica y práctica política, con las limitaciones de los modelos democráticos basados exclusivamente en los procesos electorales periódicos. De hecho, esto significó que las corrientes entre el sandinismo que tenlan la opción socialista, terminaran por imponerse en las orientaciones del gobierno revolucionario.

El modelo de democracia participativa que se fue creando, organizó su funcionamiento promoviendo la participación directa del pueblo a partir de su propio centro de trabajo o su residencia. Un ejemplo de esa participación -inmediatamente después del triunfo de la revolución-, se dio cuando los trabajadores pusieron en funcionamiento la producción tanto industrial como agrícola, sin coordinación gubernamental, 
sucediendo to mismo con la vida comunal y social en los barrios urbanos y comunidades rurales. Es decir, la sociedad se fue conformando de forma natural como una democracia participativa.

En torno al surgimiento de un modelo democrático con esas características, hay que sefalar que no se trató de un tipo de organización de la sociedad buscado con antelación. Existia una demanda democrática de la población, que era concebida por el sandinismo como el gobiemo del FSLN. En el fondo se trataba de la concepción del partido de vanguardia, partido clasista que representaba a las clases populares y que por su medio se consumaba la democracia.

En las tradiciones políticas sandinistas el uso del concepto democracia participativa no se generalizó hasta después del triunfo. La idea más en boga en el FSLN y en general dentro de las organizaciones revolucionarias, en términos de organización democrática de la sociedad, era el centralismo democrático, y los consejos revolucionarios de los trabajadores, capaces de asumir, bajo la dirección del partido, la construcción de un régimen socialista ${ }^{10}$.

\section{Centrallsmo y democracia}

Y si bien la sociedad civil se incorporó mayoritariamente al modelo participativo, las contradicciones que generó, debido a su carácter radical anti-capitalista han debilitado también la construcción de un modelo democrático. La naturaleza socializante que los sectores populares impusieron como parte del nuevo modelo participativo -el que contó con el beneplácito del FSLN - fue excluyente y liquidante de quienes defendian la propiedad privada individual y un espacio para las opiniones y la militancia no concordantes con el poder estatal y la autoridad del FSLN.

Pero de la misma forma en que la sociedad civil popular, $y$ el nuevo poder estrangulaban las alternativas que defendian la propiedad privada y la independencia del FSLN, en nombre de la revolución, también se mostró la incapacidad de generar condiciones para sostener la autonomla de los trabajadores, desarrollándose una tendencia a centralizar la economia en manos del Estado, en lugar de una economia autogestionada por los productores directos. Además, esa tendencia centralizadora en la economia, tenia su contraparte politica, que pretendia excluir del juego por el poder a otras fuerzas políticas de la sociedad. De hecho el FSLN en el gobierno fundió su existencia en la gestión estatal, haciéndose diticil distinguir los intereses del partido de los del Estado.

Esta contradicción, sub-estimada por el sandinismo y desde la 
izquierda, polarizó en contra de la revolución a sectores importantes de la población, a quienes se había tomado en cuenta durante la lucha contra la dictadura"'.

Por ese camino la sociedad comenzó a enredarse en una contradicción que aún no puede solucionar. El modelo que pretendia el pluralismo, la economía mixta y el no-alineamiento, en la medida que bs sectores populares le imprimían el sello exclusivo sandinista, socavaba sus propias bases, generando las condiciones para un mayor fraccionamiento de la sociedad, sin poder encontrar por ese camino, al mismo tiempo, una alternativa que sirviera para fortalecer la autogestión popular e impidiera la centralización estatal. Parecia como si la sociedad reaccionaba con incapacidad de recrear un modelo para el que no estaba preparada. En otras palabras las fuerzas productivas encontra= ban dificultad de adaptarse a un proceso de transformaciones muy justificado ideológicamente, pero que se contradecia con las posibilidades de implementarse.

Esto planteó una disyuntiva que ha sido poco tratada en la revolución, a saber, qué relaciones establecer con los grupos minoritarios de la sociedad civil. Lo más común ha sido defender los intereses generales de las mayorias, sin detenerse a contemplar las contradicciones que se producen en la base por efecto del aislamiento de algunos sectores. $Y$ por supuesto esto trae consecuencias serias en una sociedad atrasada, donde grupos relativamente pequehos juegan un papel aún necesario en la producción y la organización social; a eso hay que agregar la agresión imperialista contra Nicaragua, que vino a reforzar la demanda de estos sectores, desarrollándose un conficto militar cuya inspiración era foránea pero que encontraba aliento en contradicciones internas. La dependencia de las relaciones de Nicaragua con el exterior, a la que mayoritariamente se ha opuesto la población, pusieron en evidencia el rol tradicional de traspatio que le ha asignado la potencia imperialista más grande del mundo ${ }^{12}$.

De hecho la sociedad se enredaba en sus propios hilos, ya que la centralización del poder en manos del FSLN, contaba con apoyo popular, que a su vez le daba legitimidad. Durante los primeros cinco años de la revolución, el modelo participativo fortaleció una impresionante red de organizaciones de masas de clara inclinación prosandinista, que cerraba los espacios a cualquier otra manifestación política. Estas organizaciones no solo eran las herederas de las masas que se insurreccionaron contra la dictadura somocista, sino que ellas mismas eran quienes enfrentaban la agresión imperialista que fue continuidad de la dictadura. 
La sociedad civil, en la euforia de su pro-sandinismo, mantenía la existencia de otras corrientes políticas, aún cuando tendía a subordinarlas al poder de la revolución, que en otras palabras, no era más que a la autoridad del FSLN. Una revisión del modelo democrático que el sandinismo promovió en sus primeros cinco ahos, permite ver una red numerosa de organizaciones en la sociedad civil $\rightarrow$ ya que antes de la revolución nunca existieron tantos sindicatos, gremios, asociaciones de mujeres, juveniles, civiles, partidos políticos o grupos religiosos-. La inmensa mayoría de ellas tenian una definición sandinista, o bien, se encontraban en la oposición cercadas por las organizaciones sandinistas que les imponian un espacio reducido para actuar.

La guerra, servía para justificar esa dinámica de la sociedad civil, y en cierta medida le daba el sustento necesario para exigir un control de las fuerzas contrarias a la revolución en el campo cívico. Sin embargo, la naturaleza misma de la guerra y su intensidad, fue obligando lenta pero sostenidamente a la revolución a redifinir su propio comportamiento, forzándola a crear espacios para la oposición. Esta reclamaba desde el triunfo de la revolución, la construcción de un modelo pluralista y de economia mixta, donde la base de la democracia fueran los procesos electorales periódicos, y que al mismo tiempo se restringiera la participación directa de la población en la gestión estatal, ya que ésta en última instancia significaba la concentración del poder en manos del FSLN. Irónicamente la historia se vengaba de los afanes participativos de las masas y del entusiasmo que el sandinismo habla manifestado por la radicalización, abandonando el tono pluralista del discurso utilizado en sus primeros dias de poder.

En la población y entre el sandinismo, si bien no se planteaba abiertamente un rechazo al pluralismo y la economia mixta, ni a los procesos electorales, tampoco habia prisa por reafirmarlos, sobre todo porque los consideraban innecesarios para el desarrollo y consolidación de la revolución. Pero la intensidad de la guerra planteó una crisis política con repercusiones continentales, la cual, para enfrentarse internamente, obligó a una apertura que abrió espacios a la oposición que incluyeron el inicio de procesos electorales periódicos. La demanda de pluralismo y economia mixta no fue totalmente satisfecha, pero se llevaron a cabo elecciones generales para Presidente y Asamblea Nacional, en las que por primera vez en la revoluciópn los partidos políticos no sandinistas tenian oportunidad de presentar programas alternos al desarrollo nacional, sin tener que depender de la tutela sandinista ${ }^{13}$. 


\section{La redifiniclón de la revolución}

En 1985, un dirigente del FSLN reconocia con mucha honestidad que la guerra habla trastocado las intenciones sandinistas de avanzar en una línea que privilegiaba el carácter socialista de la revolución.

"La revolución sandinista nace en un espacio geopolítico continental, en el patio trasero norteameircano... Este factor geopolítico nos ha obligado, independiente de nuestra voluntad, al desarrollo del pluralismo político y la economía mixta. El desarrollo de esta táctica se ha ido convirtiendo en estrategia y hoy, la economla mixta, por ejemplo, no es una opción operativa ni un camuflaje, es una estrategia ${ }^{14 "}$

Esta posición, era ya sin dudas la aceptación en el sandinismo, de que la revolución no podia continuar con un programa que ignoraba los planteamientos de un sector minoritario pero importante de la población. La alternativa más viable resultó sin dudas el retorno hacia un programa de cuño más liberal, donde el camino socialista es apenas un planteamiento hacia el futuro, que en estos momentos tiene muy poca importancia.

Más adelante, y a pesar de las declaraciones socialistas de los dirigentes sandinistas, y a una postura fuerte frente a los intentos de la extrema derecha de boicotear los programas de recuperación de la economia ${ }^{15}$, todo parece indicar que las expectativas sobre la revolución socialista mundial han pasado a segundo plano, fortaleciendose la idea de un modelo de corte occidental ${ }^{16}$, socialdemócrata o por lo menos muy cercano a ella. Otro dirigente sandinista, declaró recientemente esa nueva opción del FSLN.

"Ahora nosotros tenemos una posición de vanguardia, ciertamente dentro del concierto latinoamericano, pero nosotros no estamos tan desligados de corrientes de avanzada socialdemócrata en América Latina... inclusive, en Centroamérica, nos acercamos más a Guatemala y a Costa Rica por la naturaleza de sus gobiernos y de su pensamiento político; pero si, sin duda nosotros somos una corriente yo dirla socialdemócrata, socialista democrática, más beligerante por la naturaleza del problema de Nicaragua ${ }^{17}$."

Estos cambios, que se presentan como un viraje de la politica sandinista, se han venido realizando después de las elecciones de 1984 , de manera tal que en la actualidad la revolución presenta un perfil participativo muy contraido, mientras la actividad politica partidaria ha ganado un lugar preponderante. Esa transición, de la movilización participativa de las masas a la movilización política de los partidos, fue 
facilitada por la debilidad militar de la contrarrevolución, en la medida que se ha profundizado su derrota por la ofensiva militar de la revolución. Las organizaciones de masas sandinistas, se han replegado a una postura de espera a los resultados de la nueva política, mientras las formas de la democracia representativa van ganando cada vez mayores espacios.

Los partidos polfticos, hasta hace pocos años muy apocados, al cumplir diez ańos la revolución han recuperado el aliento y se presentan como los protagonistas de la democracia, con la misma intensidad con la que antes se presentaron las organizaciones de masas. La única, pero fundamental diferencia, radica en que estos no se sustentan en un apoyo popular como el que ha demostrado el FSLN, sino en la crisis económica provocada por la guerra (y por supuesto por los errores en la conducción política y económica del pais), y en la transferencia de la ayuda norteamericana de la guerra a la oposición civica.

En la actualidad, el financiamiento norteamericano que antes se destinaba a la guerra, se dirige a crear partidos políticos capaces de realizar lo que la contrarrevolución no fue capaz de hacer, es decir, lograr la derrota del sandinismo.

El país vive el ambiente electoral, con la participación de veinte y un partidos políticos, sin que esto aparentemente signifique una consolidación de la democracia. La demanda política, creada por los Estados Unidos, divide la polémica electoral, no tanto a lograr una victoria opositora que no aparece muy clara, sino a desprestigiar los intentos sandinistas de realizar un proceso que ratifique el respaldo popular que reivindica, y del que ha mostrado suficientes evidencias.

El conjunto de este fenómeno, ha llevado a conformar un modelo sumamente enredado. La demanda popular para intensificar la revolución choca con las limitaciones de un pais atrasado, al que se le niega el derecho a ser independiente, pero que tercamente persiste en ello. La democracia como participación colectiva, y como proceso de transformaciones que pretende el socialismo, encuentra limitaciones objetivas y tiende a someterse a las presiones que le liegan sobre todo de afuera. El panorama, nada claro, tiende a confundir, y si bien, todo indica que el respaldo popular por la revolución se mantiene, en la medida que la democracia participativa encuentra limitaciones, las masas tienden a vacilar y a manifestarse una gran indecisión sobre las alternativas a seguir ${ }^{18}$.

Quizas la mejor interpretación de la situación actual la da Tomás Borge, cuando reconoce con mucho tino lo complejo del proceso 
revolucionario y los virajes a que se ha visto sometido el sandinismo. Intentando explicar las contradicciones que a la revolución le producen las demandas participativas de la población, con las presiones para la implantación de un modelo restrictivo de esta, Borge dice:

"En todo caso, los errores o fallos que hayan incidido en cierto repliegue de la participación popular en determinados aspectos, hay que atribuirlos a la dirección revolucionaria. Pero también hay que entender que estos errores son inevitables, en una situación como la que vivimos con nuestra revolución acosada por un gobierno norteamericano particularmente agresivo... El pluralismo político, la economia mixta y los rasgos más generales de la revolución tienden a confundir a las masas. No hay un proyecto ideológico, ni puede haberio, tan diáfanamente definido como el que existió en Cuba. El nuestro es un proyecto enredado, complicado, y los proyectos enredados confunden a las masas. Hasta ahora no hemos sido capaces, $y$ es posible que no seamos lo suficiente capaces, de lograr que el pueblo entienda toda esta complejidad. A veces tampoco hemos sido lo suficiente receptivos para captar las inquietudes populares. Otras ni siquiera nosotros tenemos claridad suticiente para entender la naturaleza extremadamente compleja de este proceso ${ }^{19 n}$.

Notas

1. Entre los estudios publicados, los más importantes son: "Democracia y Revolución en las Américas", de Orlando Núñez y Roger Bourbach, Editorial Vanguardia, Managua 1987; "Sandinismo, Marxismo, Cristianismo: La Confluencia" de Giulio Girardi, Centro Ecuménico Antonio Valdivieso, 1987; "Perfiles de la Revolución Sandinista" de Carlos Vilas, Editorial Nueva Nicaragua, 1988.

2. La Revista de la Asociación de Cientificos Sociales de Nicaragua (ANICS); Cuadernos de la Sociologla de la Escuela de Sociologla y la Revista Encuentro de la Universidad Centroamericana, contienen los principales ensayos sobre la democracia publicados en el país. Se han publicado también varios libros que recojen los ensayos presentados en los congresos de ANICS, asI como en ediciones del CRIES, INIES y CIERA.

3. En 1986 la Editorial Vanguardia editó una colección de discursos de Víctor Tirado, bajo el nombre de "Nicaragua: una Nueva Democracia en el Tercer Mundo". Tirado es Comandante de la Revolución, miembro del directorio sandinista, y responsable partidario por el FSLN de las organizaciones laborales y sociales de filiación sandinista.

4. Algunas de ellas son: Envlo, del Instituto Histórico Centroamericano; Pensamiento Propio, del CRIES; Revolución y Desarrollo, del CIERA; Amanecer, del Centro Ecuménico Antonio Valdivieso; Revista de Ciencias 
Sociales, de la Asociación de Cientificos Sociales de Nicaragua (ANICS); Cuadernos de Sociologla, de la Escuela de Sociologla; Revista Encuentro, de la Universidad Centroamericana; BoletIn Socioeconómico, Cuadernos de Investigación y Foro Debate, del INIES; Wani, del CIDCA.

5. Desde el exterior, sobre todo en Costa Rica y Estados Unidos, funsionan otros partidos políticos de derecha, los cuales operan como base politica de la contra.

6. No vamos a insistir en ellos por la falta de valor académico de los trabajos publicados, que en última instancia no hacen más que repetir acusaciones fabricadas en Washington, sin preocuparse por la veracidad de la informaciónque ofrecen. La Editorial Libro Libre, de Costa Rica, ha publicado; Nicaragua, de varios autores; Frente a dos Dictaduras, de Jaime Chamorro; Nicaragua, Regresión en la Revolución, de José Luis Velázquez y Arturo Cruz; Nicaragua, Sociedad Civil y Dictadura, de José Luis Velázques; Lo que se Quiso Ocultar, de Roberto Cardenal.

7. Los tres tonos partidarios responden a la Tendencia Proletaria, la Tendencia Guerra Popular Prolongada y La Tendencia Insurreccional; estas fueron las tres tendencias en las que se dividió el sandinismo antes de 1979.

8. La nacionalización abarcó también la banca, el comercio exterior, el subsuelo y las plataformas marltimas, descabezando los ejes centrales de acumulación de la burguesla.

9. La contiscación de la propiedad es un acto por el cual esta pasa al control del Estado (para uso estatal o su distribución a los campesinos), sin que el antiguo propietario tenga derecho a indemnización; la expropiación por otro lado, implica la obligación del Estado de pagar la propiedad a su antiguo dueño, a precios de mercado después de haber sido evaluada por expertos.

10. La demanda de un modelo con el nombre de democracia participativa antes de 1979 era muy poco conocido en Nicaragua. Hoy por el contrario, es utilizado por corrientes pollticas de signos contrarios, sobre todo por las distintas acepciones con las que se presenta la izquierda marxista y los grupos de cristianos revolucionarios, llegando hasta las corrientes conservadoras socialcristianas.

11. Todo indica que en el desarrollo de las revoluciones las mayorías terminan, también, ignorando a las minorlas. Esta ignorancia no puede evitar, sin embargo, que las minorlas sean una fuerza importante. En el caso de la revolución sandinista, las elecciones de 1984 mostraron que las minorlas representaban cuando menos el $33 \%$ de la población. Un ejemplo de lo que puede significar una minorla lo tenemos on el desarrollo de la contrarrevolución. A finales de 1986 los efectivos de las bandas alcanzaban según estimaciones oficiales unos 20 mil hombres en armas. Es decir, cuando menos, la contra llegó a contar con una base que incluia cerca de sesenta mil personas activas militarmente, sin contar otro tipo de adhesiones pasivas. El cálculo para esta cifras parte de considerar que cada hombre en armas necesita de uno a dos hombres de apoyo en la población civil.

12. Para los Estados Unidos la opción libertaria y socialista de la revolución 
sandinista, le planteó la alternativa de aceptar la ruptura de su control hegemónico en la región, reaccionando con la agresividad típica del imperialismo, promoviendo contra Nicaragua la guerra de agresión más fuerte que ha vivido cualquier pais latinoamericano en lo que va del presente siglo.

13. Hasta las elecciones de 1984, la política estaba condicionada a la voluntad del FSLN, quien en última instancia era el que determinaba quien y como participaba del juego político. El consejo de Estado, que hizo el papel de parlamento de la revolución, era nombrado directamente por el FSLN, quien escojla, en negociaciones directas con los partidos, el número de representantes que cada uno podía tener.

14. "El nuestro es un proyecto enredado": Tomás Borge, entrevista en Pensamiento Propio, INIES-CRIES, año III, No. 24 junio-julio 1985, Managua, Nicaragua.

15. En la medida que la crisis económica se ha venido endureciendo, los dirigentes sandinistas han apelado a un lenguaje radical, mientras avanzan en relormas que niegan ese discurso, fortaleciendo un papel cada vez más favorable para la producción indvidual capitalista, que hace retroceder algunos de los logros alcanzados por la democracia participativa, particularmente en la profundización de la reforma agraria, la cual ha sido virtualmente embargada. Sin embargo, estas reformas están dentro del marco de un programa de concertación nacional, que pretende mantener bajo el control popular esta retirada. De ahl que los intentos de romper la política de concertación estén sometidos a la aplicación rigurosa del marco jurídico creado en los diez años de revolución.

16. Recientemente, tanto el Presidente de la República, como el Comandante Tomas Borge, han dado declaraciones en el sentido de que el socialismo que busca Nicaragua se parece más a la experiencia de los palses del Norte de Europa, que al socialismo del Este europeo.

17. Entrevista a Jaime Wheelock Roman, en el períodico "Esta Semana", Vol. 2 No. 27, mayo de 1989, San José, Costa Rica.

18. En todas las encuestas de opinión realizadas durante el último año en Nicaragua, se aprecian porcentajes superiores al cuarenta por ciento de respuestas que no apuntan ni al FSLN ni a la oposición. Un poco más del treinta por ciento de los encuestados optan por el FSLN, mientras la oposición (los veinte partidos juntos) supera un poco el $20 \%$ de respuestas favorables. Las encuentas a que nos referimos han sido realizadas por INOP-ITZTANI (privados) y la Fundación Manolo Morales de la oposición.

19. "El nuestro es un proyecto enredado"; Tomás Borge, en Pensamiento Propio, año III, No. 24, junio-julio 1985, Managua Nicaragua. 